\title{
Homoeopathy for COVID-19: A Public Health Emergency
}

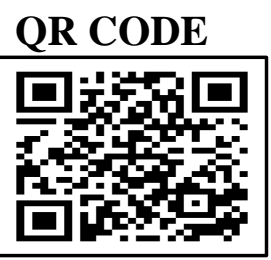

\section{KANAGAVALLI MATHIVATHANAN iD}

SARS-CoV-2 (COVID-19) has become the major public health concern. As of May $31^{\text {st }}$, 2021 more than 3.5 million deaths have been reported due to COVID19. ${ }^{1}$ Appropriate behaviour like hand washing, wearing mask, maintaining social distance can inhibit the COVID-19 transmission. Mild cases of COVID-19 should practice action plan of home quarantine, hygiene measures, stockpiling of food, vitamin supplements and herbal remedies. Severe cases require hospitalization and prompt adaptable treatment strategy may reduce mortality.

Low-and middle-income countries like India with poor public health strategy faced high mortality rate. Unfortunate sudden surge of COVID-19 second wave in India made a catastrophic disaster. Weak surveillance, poor health care facilities, paucity of hospital beds and testing services leads to health inequity and reveals unpreparedness. India's healthcare system is evolved with usage of conventional as well as complementary therapies in decades. Unequal quality treatment and vaccine distribution, economic burden leaves poor people deprived of healthcare facilities. Easy accessibility and cost-effectiveness of complementary therapies especially Homoeopathy, contributes to health equity. Additionally, continuous efforts of Ministry of AYUSH in creating awareness and distributing prophylactic COVID-19 medicines increased the use of Homoeopathy. Hence, it is important to emphasize the significance of Homeopathy in public health emergency.

Homoeopathy was founded by Dr.Samuel Hahnemann in late 170o's, based on symptomatic individualized treatment. Effectiveness of Homoeopathic medicine is significant in epidemics. Historic evidence suggested Homoeopathic treatment is effective in reducing mortality of scarlet fever, cholera and spanish flu. Homoeopathy in epidemics is subjected to Genus Epidemicus (GE), wherein medicine is selected on characteristic signs and symptoms. GE is used as preventive and curative treatment. $^{2}$
Besides, scientific evidence reported significant outcomes in Chikungunya and Japanese Encephalitis after homoeopathic intervention. Rapid recovery is shown in cases of Influenza by Homeopathic medicines Arsenicum album and Bryonia alba. ${ }^{3}$ However, scientific exploration of efficacy/effectiveness of Homoeopathy in COVID-19 is yet to be generated.

Health advisory by Ministry of AYUSH, GOI proposed Arsenicum album as prophylactic for COVID-19. Previous evidences suggested that Arsenicum album is effective in Influenza like Illness (ILI). Similarities of early expression of the COVID-19 and ILI, repurposing of Arsenicum album in COVID-19 may reduce mortality and morbidity. There is a constant variation in the manifestations of dynamic epidemic transmission. Keeping in view, GE may also vary according to symptom clusters of epidemic and geographical location. Evidence from COVID-19 case reports by China doctors reported Bryonia alba and Gelsemium as the most indicative remedy. ${ }^{4}$

A single blind controlled trial conducted in Bhopal COVID-19 hospital showed hasty recovery in group receiving homoeopathy as compared to modern medicine. Integrative treatment of Homoeopathy with conventional medicine reported early recovery and reduced mortality rate in moderate to severe COVID-19 cases and reduced the severity of infection in geriatric age groups. A study in Delhi prison complexes showed beneficial prophylactic effect of the Arsenicum album in mitigating COVID-19 infection. Another study in containment zone in Maharashtra police, potential prohylactic effects of Arsenicum album were observed. ${ }^{5}$ Repurposing of homoeopathic medicines as an add-on or stand-alone approach provides early recovery and decreased mortality.

Evidences from clinical experience suggested adjuvant homeopathic treatment in interstitial pneumonia demonstrated beneficial outcome in nonresponders to the conventional medicine. ${ }^{6}$ Increase in 
homoeopathy usage is due to the safe nature and inexpensive treatment. Despite aforementioned studies, Holandino $\mathrm{C}$ et al. reported insignificant effect of homoeopathic complex medicine in sick and healthy groups. ${ }^{7} \mathrm{GE}$ of the particular epidemic is fruitful than homoeopathic complex.

Growing body of literature urges integrative approach has potential benefits. Yet, challenges encounted by policy makers due to lack of high-quality data demonstrated prophylactic and curative effects of homeopathic medicines. Ministry of AYUSH, GOI launched "AYUSH Sanjivani" application to generate the high-quality evidence. Target of Sanjivani app is to reach 50 lakh people and to build the strong evidence of usage of AYUSH advocacies in COVID-19. A cross-sectional analysis from the Sanjivani app showed that Homoeopathy and Ayurveda are being widely used among AYUSH system. Arsenicum album was extensively used as compared to other system prophylaxis. Understanding the data trends from app, ought to put forward robust clinical trials in Homoeopathy. ${ }^{8}$

Finally, COVID-19 pandemic revealed long term neglect of public health in India. Pluralistic treatment approach is required for benefitting the poor families. In addition, welcoming attitude about Homeopathy has been observed in doctors from countries like China and Spain. To strengthen and implement the policies, methodologically rigorous clinical trials in homoeopathy are warranted.

\section{REFERENCES}

1. WHO. Coronavirus (COVID-19) Dashboard (Online Article). Available from: https://covidıg.who.int/ [Last Accessed on $1^{\text {st }}$ June, 2021]

2. Hahnemann S. Organon of Medicine. $6^{\text {th }}$ ed. Translated by William Boericke. New Delhi: B Jain Publishers; 1991.

3. Chaudhary A, Khurana A. A review on the role of homoeopathy in epidemics with some reflections on COVID-19 (SARS-CoV-2). Indian Journal of Research in Homoeopathy 2020;14(2):100. https://doi.org/10.4103/ijrh.ijrh_34_20

4. Bala R, Srivastava A. Historical Journey of Homoeopathy during Epidemic Diseases in the Light of 2019 Novel coronavirus pandemic. Int J Sci Healthc Res. 2020;5:215-33.

5. Khurana A. Kumar Shaji RT, editors. Proceedings of World Homoeopathy Day 2021 conferenceHomoeopathy- Roadmap for Integrative Medicine. New Delhi: Central Council of Research in Homoeopathy; 2021.

6. Tramontana A. COVID-19 Pneumonia: A Potential Role of Homeopathy. Homeopathy. 2021;110(o1):70-1. https://doi.org/10.1055/s-0040-1721063

7. Holandino C, Oliveira AP, Vilhena EC, Sanches TR, Bolognani FD, Torres ET, Gouveia CM, Campos VE, Paiva JP, Homsani F, Freitas FJ. Homeopathy and the COVID-19 pandemic: quasi-experimental observational study. Int J High Dilution Res. 2021:910. https://doi.org/10.51910/ijhdr.v20i1.1082

8. Srikanth N, Rana R, Singhal R, Jameela S, Singh R, Khanduri S, Tripathi A, Goel S, Chhatre L, Chandra A, Rao BC. Mobile App-Reported Use of Traditional Medicine for Maintenance of Health in India During the COVID-19 Pandemic: Cross-sectional Questionnaire Study. JMIRx med. 2021;2(2):e25703. https://doi.org/10.2196/25703 